\title{
THE VOCABULARY OF SCIENCE-POPULAR MEDICAL DISCOURSE (AS EXEMPLIFIED IN GERMAN ONLINE MEDIA)
}

\author{
Nikolay L. Shamne \\ Volgograd State University, Volgograd, Russia \\ Ekaterina V. Shishkina \\ Volgograd State Medical University, Volgograd, Russia
}

\begin{abstract}
Abstact. The paper analyzes the vocabulary of the German science-popular medical discourse as exemplified in the German online media. The relevance of the study is due to the growing interest of non-professional participants of medical communication, as the main recipients of this institutional discourse, to the processes of self-diagnosis and self-treatment, which require the expansion of medical knowledge. The paper examines the texts of more than 40 publications in detail, establishes their distinctive structural features, genres and vocabulary. It is shown that the dominant genre in the studied type of discourse is a science-popular article. It has been established that the lexicon of the type of discourse under study includes common vocabulary, general scientific vocabulary and medical terminology. We consider some ways to clarify the terms: explanations, the use of doublet forms, hypertext links, as well as the use of international word-building elements. The types of phraseological units and metaphors that function in science-popular medical discourse are characterized: it is shown that phraseological units based on the similarity of the phenomena of the medical field with the phenomena of the animal world, as well as with everyday life realities, and metaphors based on images of the game, war and court are used more frequently. The results of the study prove the need to expand the scope of study of medical science-popular discourse by considering it in linguopragmatic and stylistic aspects.

Key words: vocabulary, medical terminology, medical phraseology, metaphor, online media, medical discourse, science-popular discourse, German language.

Citation. Shamne N.L., Shishkina E.V. The Vocabulary of Science-Popular Medical Discourse (as Exemplified in German Online Media). Vestnik Volgogradskogo gosudarstvennogo universiteta. Seriya 2, Yazykoznanie [Science Journal of Volgograd State University. Linguistics], 2018, vol. 17, no. 4, pp. 170-179. (in Russian). DOI: https://doi.org/ 10.15688/jvolsu2.2018.4.16
\end{abstract}

\section{ОСОБЕННОСТИ ЛЕКСИЧЕСКОГО СОСТАВА МЕДИЦИНСКОГО НАУЧНО-ПОПУЛЯРНОГО ДИСКУРСА (НА МАТЕРИАЛЕ НЕМЕЦКОЯЗЫЧНЫХ ИНТЕРНЕТ-ИЗДАНИЙ)}

\author{
Николай Леонидович Шамне \\ Волгоградский государственный университет, г. Волгоград, Россия \\ Екатерина Викторовна Шишкина \\ Волгоградский государственный медицинский университет, г. Волгоград, Россия
}

Аннотация. В статье анализируется лексический состав немецкоязычных медицинских научно-популярных интернет-изданий. Актуальность исследования обусловлена растущим интересом непрофессиональ- 
ных участников медицинской коммуникации как основных адресатов данного институционального дискурса к процессам самодиагностики и самолечения, требующих расширения медицинских знаний. Детальному изучению в статье подвергаются тексты статей более чем 40 изданий, определяются их структурные особенности, жанры и лексический состав. Показано, что доминирующим жанром дискурса исследуемого типа является научно-популярная статья. Установлено, что в лексикон этого дискурса входят общеупотребительные и общенаучные лексические единицы, медицинская терминология. Рассмотрены способы разъяснения терминов: пояснение, использование дублетных лексем, гипертекстовых ссылок, интернациональных словообразовательных элементов. Охарактеризованы типы фразеологизмов и метафор, функционирующих в научно-популярном медицинском дискурсе: чаще других используются фразеологизмы, возникшие на основе сходства явлений медицинской сферы с явлениями мира животных, а также с бытовыми реалиями, и метафоры, в основу которых положены образы игры, войны, суда. Результаты исследования доказывают необходимость расширения рамок изучения медицинского научно-популярного дискурса посредством рассмотрения его в лингвопрагматическом и стилистическом аспектах.

Ключевые слова: лексика, медицинская терминология, медицинские фразеологизмы, метафора, интернет-издание, медицинский дискурс, научно-популярный дискурс, немецкий язык.

Цитирование. Шамне Н. Л., Шишкина Е. В. Особенности лексического состава медицинского научнопопулярного дискурса (на материале немецкоязычных интернет-изданий) // Вестник Волгоградского государственного университета. Серия 2, Языкознание. - 2018. - Т. 17, № 4. - C. 170-179. - DOI: https:/doi.org/ 10.15688/jvolsu2.2018.4.16

\section{Введение}

Современная лингвистика все больше внимания уделяет различным видам междискурсивных отношений в связи с недостаточной изученностью междискурсивного взаимодействия как многокомпонентного коммуникативно-прагматического явления. Отечественные и зарубежные лингвисты нередко обращались к указанной проблеме [Денисова, 2008; Косицкая, 2005; Костяшина, 2010; Резанова, 2008, 2012; Силантьев, 2004, 2006; Филлипс, Йоргенсен, 2004 и др.].

Под междискурсивным мы понимаем взаимодействие двух и более видов дискурса. При этом необходимо отметить, что оно имеет иерархический характер, то есть один из дискурсов занимает доминантную позицию. Как отмечает О.В. Соколова, «взаимодействие дискурсов происходит одновременно на лингвистическом и экстралингвистическом уровнях, задействуя суперструктуру и макроструктуру дискурсов. Процесс взаимодействия определяется генетической связью, параллельным развитием и апроприацией отдельных дискурсивных элементов, интерференцией как результатом влияния базового (или доминантного) дискурса и обратным воздействием со стороны со-дискурсов в новой социокультурной ситуации» [Соколова, 2014, с. 26].

В рамках коммуникативного подхода к языку исследователи рассматривают дискурс как текст, погруженный в ситуацию общения [Карасик, 2000, с. 5-6]. При этом системообразующим фактором здесь выступает область применения языка. Каждый тип дискурса обладает системными свойствами, которые представлены лингвистическими средствами на разных языковых уровнях. В.И. Карасик выделяет следующие категории, на которых основано построение дискурса любого типа: участники общения (их статусы и роли); условия общения (время и место общения коммуникантов); организация общения (мотивы, цели и стратегии); способы общения (канал и жанр общения) [Карасик, 1998, с. 197].

В настоящей статье представлены результаты изучения лексики медицинского научно-популярного дискурса в лингвистическом аспекте. Источниками языкового материала послужили более 40 научно-популярных интернет-изданий (некоторые из них имеют печатные аналоги): Diabetes Ratgeber, Apotheken Umschau, Gesundheitsthema, Apotheken Kurier, Gesunde Medizin, Apotheken Medien $\mathrm{GmbH}$ \& Co. KG, Neue Apotheken Illustrierte, Rentner Ratgeber, Baby und Familie, Medizin Aspekte, Ausgeglichenes Leben - Anleitungen fürs Wohlbefinden, Medizin Compact, Benyoo, Patric Heizmann Blog, E-Health-Care, Kompass Gesundheit, Fachverlag für Gesundheitswissen, Rechtsdepesche für das Gesundheitswesen, Fit Gesund Schön, RatgeberGesund.de, Gesumag.de, Gesund \& Vital Magazin, Gesundheit aktuell, 


\section{МАТЕРИАЛЫ И СООБЩЕНИЯ}

Ratgeber Wellness und Gesundheit, Gesundheit und Wissenschaft, Patienten-Bibliothek, Gesundheitsblock, Gesundheitsfocus, TABU, Gesunex - aktiv gesund leben, Spektrum Medizin, Suchthilfe-Magazin, Mabuse Verlag, Gute PillenSchlechte Pillen, Topfit, KaleidoscopeGesundheitsnachrichten, Reformhaus Kurier, Redspa Media $\mathrm{GmbH}$, das Magazin für BadenWürttemberg, Die Welt der medizinischen Blogs, Medizin-Welt: Gesund durch Wissen, Vigo, Ärztezeitung, (в списке источников указаны только сайты изданий, материалы которых цитируются в статье).

Интернет-издание представляет собой виртуальный ресурс с функциями СМИ, содержащий актуальные сведения публицистического характера. Жанр интернет-издания идентичен традиционному печатному выпуску и зачастую полностью повторяет его содержание. Отличительными структурными особенностями такого типа изданий являются: дополнительный контент (аудио- и видеоматериалы, приложения, тесты, ссылки); необозримость целого тематического блока (список рубрик, заглавия и аннотации наиболее популярных статей); взаимосвязь текстов через активные ссылки; большее (в сравнении с печатным изданием) количество иллюстраций (адресат взаимодействует с информацией с помощью вербальных и невербальных средств); интерактивность (возможность оценить статью, распространить информацию через аккаунт в социальной сети, обсудить ее в онлайн-конференции, подписаться на издание, перейти на сайт рекламируемого товара, заказать товары и услуги) [Шамне, Шишкина, 2017, с. 145].

Исследованные источники характеризуются полидискурсивностью со свойственным ей функциональным пересечением таких институциональных дискурсов, как медицинский, научный, научно-популярный, наивно-медицинский, рекламный, публицистический, педагогический и т. д. Базовым в рассматриваемых интернет-изданиях является медицинский дискурс, поскольку на его основе формируются важнейшие функционально-тематические блоки, стратагемно-тактические комплексы, целевые установки. Медицинский научно-популярный дискурс реализует две целевые установки - информирование получателя и попу- ляризация научного знания. Основной целевой установкой является информирование, а популяризация научного знания способствует ее реализации.

Исследуемый дискурс демонстрирует разнообразие жанров: интервью, социологическое исследование, обзор, рекламный текст [Шишкина, 2018]. Основным жанром немецкоязычного научно-популярного медицинского интернет-издания является научно-популярная статья. Читая статьи, получатель, как правило, не имеющий специализированных медицинских знаний, формирует собственное мнение относительно проблемы, знакомится с медицинской терминологией, базовыми понятиями научного знания. Это способствует оптимальному сотрудничеству и эффективному общению медицинского представителя как агента дискурса и пациента как клиента дискурса. Успешность такой коммуникации обеспечивается тем, что агенты научно-популярного дискурса учитывают его полидискурсивный институциональный характер: медицинские работники обращаются не к своим коллегам, как это происходит в научном медицинском дискурсе, а к представителям наивного медицинского дискурса, которым требуется оказание квалифицированной медицинской помощи.

Специфика медицинского научно-популярного дискурса проявляется прежде всего в его лексической наполняемости.

\section{Медицинская терминология}

\section{в научно-популярном медицинском} дискурсе

Лексикон немецкоязычных медицинских научно-популярных статей составляют общеупотребительные слова, общенаучные слова и медицинская терминология. Методом количественных подсчетов было установлено соотношение количества употреблений лексических единиц, что отражено в диаграмме (см. рис. 1). Объем общеупотребительной лексики значительно превышает объем общенаучной и терминологической. При этом, попадая в научно-популярный медицинский дискурс, узкоспециализированные тексты адаптируются для непрофессионального получателя. 
Специальные медицинские термины вводятся в текст научно-популярной статьи несколькими способами. Терминологические единицы объясняются описательно или при помощи дублетных лексем, например:

(1) 2010 veröffentlichten dessen Forscher erste Ergebnisse: Menschen mit metastasiertem Hautkrebs (Melanom), die mit dem Antikörper Ipilimumab behandelt wurden, lebten dreieinhalb Monate länger als Betroffene, die das Mittel nicht erhielten (Immuntherapie gegen Krebs. http://www.apotheken-umschau.de)- 'B 2010 г. исследователи опубликовали первые результаты: люди с метастазируюшим раком кожи (меланомой), которых лечили при помощи антител Ипилимумаб, прожили на 3,5 месяца дольше, чем те, которые не принимали это средство' (здесь и далее перевод с немецкого наш. $-H$. $U$., $E$. $W$.).

(2) Insbesondere Diabetes, eine Schilddrüsenunterfunktion oder eine Blutarmut (Anämie) gilt es abzuklären, da auch diese Störungen hinter dem Erschöpfungszustand stecken können (Krebs-Fatigue: Anhaltend erschöpft. http://www.apothekenumschau.de) - 'Могут быть выявлены диабет, проблемы с щитовидной железой или малокровие (ане- мия), поскольку эти нарушения также могуг являться причинами утомляемости'.

(3) Bauchspeicheldrüsenkrebs (Pankreaskarzinom) ist eine bösartige Gewebsveränderung der Bauchspeicheldrüse (Pankreas) (Bauchspeicheldrüsenkrebs (Pankreaskarzinom). http://www.apotheken-umschau.de) - 'Рак поджелудочной железы (панкреатическая карцинома) представляет собой злокачественное изменение тканей поджелудочной железы (панкреаса)'.

Формат интернет-издания позволяет также интегрировать внутритекстовые ссылки (см. рис. 2), переходя по которым читатель получает справочные сведения о том или ином медицинском термине, что значительно облегчает понимание текста и способствует выполнению основной целевой установки.

В медицинских научно-популярных статьях часто используются термины, в состав которых входят интернациональные словообразовательные элементы например antibakteriell, Mikroorganismus, Makrovirus, Multivitamine, extradynamisch:

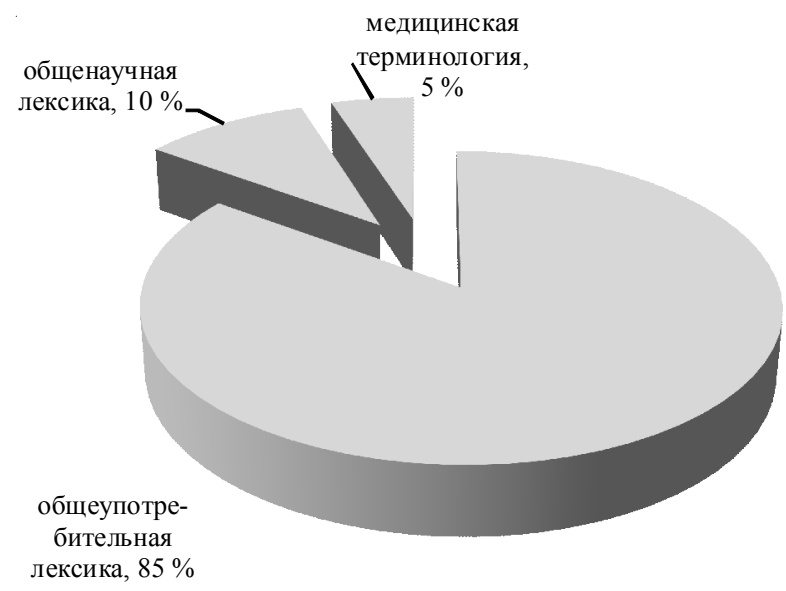

Рис. 1. Лексический состав немецкоязычной медицинской научно-популярной статьи

Der zweite Patient, den Ulrich Keilholz mit dem neuen Medikament behandelte, schien ein aussichtsloser Fall: ein 54 Jahre alter Mann, dessen Hautkrebs breit gestreut hatte. Die Tumorzellen wucherten auf der Leber, im Gehirn, auch die Lymphknoten in den Achseln waren befallen. "Normalerweise hätte man da eine Chemotherapie gemacht und noch zwei oder drei Monate Lebenszeit erwartet", sagt Professor Keilholz, der am Berliner Uniklinikum Charité das "Comprehensive Cancer Center" leitet.

Рис. 2. Пример реализации внутритекстовых ссылок в статье (Immuntherapie gegen Krebs. http://www.apotheken-umschau.de) 
(4) Mehrere Tausend Bakterienarten, die im menschlichen Verdauungstrakt vorkommen, sind schon identifiziert. Dabei existiert eine Kombination von Mikroorganismen, die alle Menschen gemeinsam haben. (Wie Darmbakterien uns beeinflußen. http:// www.apotheken-umschau.de) - 'Тысячи видов бактерий, которые встречаются в желудочно-кишечном тракте человека уже идентифицированы. При этом существуют общие для всех людей комбинации микроорганизмов'.

Наличие таких элементов в структуре термина делает пояснения в научно-популярном тексте избыточными.

\section{Заимствования в научно-популярном медицинском дискурсе}

Заимствования, функционирующие в научно-популярных медицинских статьях, условно можно разделить на две группы. К первой относятся заимствования, вошедшие в немецкий язык давно, уже усвоенные им, поэтому не воспринимающиеся носителями языка как иноязычные: die Narkose (от греч. nárkōsis 'оцепенение, паралич, парез') - наркоз; die Anästhesie (от греч. anaisthēsía - 'нечувствительность, невосприимчивость') - анестезия; die Halluzination (от лат. alūcinātio, halūcinātio - 'необдуманный разговор, мечтания') - галлюиинация; die Akupunktur (от лат. Acus - 'игла' и лат. Pūnctūra - 'укол') иглоукальвание, акупунктура; die Immunität (от лат. Immūnis - 'свободный от наложений') - иммунитет. Большинство таких слов составляют термины, заимствованные из классических языков медицины - греческого и латинского. Иноязычные слова данной группы в немецкоязычных медицинских научно-популярных статьях встречаются часто и, как правило, без дополнительных пояснений:

(5) Infektionskrankheiten zählen zu den häufigsten Todesursachen weltweit. Anstecken kann man sich auf verschiedensten Wegen mit Erregern wie Bakterien oder Viren (Infektionen erkennen und behandeln. http://www.apothekenumschau.de) - 'Инфекционные заболевания относятся к самым распространенным причинам смерти по всему миру. Заразиться ими можно через различных возбудителей, таких как бактерии и вирусы'.
Ко второй группе относятся лексемы, широко распространенные не только в научно-популярном, но и собственно медицинском дискурсе и имеющие немецкоязычные синонимы. Например, немецкое слово die Straffung заменяют англицизмом der Lifting (от англ. lifting - 'подъем'), при этом оба термина означают подтяжку кожи:

(6) So entsteht eine Art Lifting-Effekt: Die spezielle Nahttechnik fixiert die Hämorride dort, wo sie anatomisch eigentlich hingehört. Diese Operation wird in einer Rückenmarks- oder Vollnarkose durchgeführt (Hämorriden: Vier BehandlungsMethoden. http://www.apotheken-umschau.de) - 'Taким образом, возникает своеобразный лифтингэффект: специальная техника наложения шва фиксирует геморроидальный узел там, где это необходимо с анатомической точки зрения. Эта операция проводится при эпидуральной анестезии или общем наркозе'.

Заимствованным синонимом для лексемы der Selbstmord (суицид) является der Suizid (от англ. suicide < от лат. sui - 'сам, себя' + caedes - 'убийство') - «акт самоубийства, совершаемый человеком в состоянии сильного душевного расстройства или под влиянием психического заболевания», a der Abstumpfung (anатия) имеет синоним die Apatie (от греч. apatheia - 'бесчувственность') - «состояние полного безразличия, равнодушия». Эта группа терминов заимствована в медицинский дискурс из дискурсов, обслуживающих другие сферы деятельности: право, психологию и т. д.

\section{Фразеологизмы в научно-популярном медицинском дискурсе}

Лексикон исследуемых текстов включает в себя многочисленные фразеологические единицы. Изучение медицинских фразеологизмов в русском языке ведется отечественными лингвистами в разных аспектах (см. например: [Гончаренко, 2014; Зубкова, 2008, 2011; Момот, Мартиросян, Газарянц, 2016; Сотников, 2013 и др.]). Так, Ю.А. Сотников составил перечень медицинских фразеологизмов русского языка, в который включил около ста единиц [Сотников, 2013, с. 4]. Е.А. Момот, А.А. Мартиросян, А.К. Газарянц предложили 
классификацию медицинских фразеологизмов русского языка, выделив группы идиом, связанных с животным миром, с мифологией, с разделами медицины, с профессиями и спортом, а также включающие фамилии ученых, слова, называющие бытовые реалии [Момот, Мартиросян, Газарянц, 2016, с. 6-7]. Несколько классификаций медицинских фразеологизмов, в основе которых лежат грамматический признак (по главному слову), семантический признак или принцип «схожести» названных объектов или явлений (значение медицинского фразеологизма обусловлено значением составляющих его слов) и др. предложено О.П. Игнатенко и Ю.Г. Фатеевой [Игнатенко, Фатеева, 2017, с. 183]. Классификации, построенные на материале русского языка, имеют универсальный характер и применимы при исследовании лексических единиц других языков.

В последние годы появились работы, посвященные медицинским фразеологизмам и в немецком языке. Так, фразеологизмы и метафоры в немецкоязычных медицинских текстах анализирует М.А. Гежинска. При этом автор выделяет следующие тематические рубрики: сложные клинические случаи; абстрактные выражения; здоровье как баланс; медицина как игра; лечение - борьба, а болезнь - враг [Gierzyńska, 2013].

Изучение фактического материала с учетом имеющихся классификаций медицинской фразеологии показывает, что большинство немецкоязычных фразеологизмов, функционирующих в научно-популярном медицинском дискурсе, связано с миром животных. Hahnentritt (петушиная походка) - «походка, характеризующаяся поочередным резким выбрасыванием нижних конечностей»; Katzenschreisyndrom (синдром кошачьего крика) - «характерный плач, напоминающий мяуканье кота»; Affenhandstellung (симптом обезьяньей лапы) - «атрофия мышц большого пальца руки»; Affenfurchen (обезьяньи склад$\kappa u)$ - «поперечная ладонная складка, напоминающая ладонный сгиб у обезьян»; Katzenpupille (кошачий зрачок) - «зрачок овальной или щелеобразной формы при сдавливании глазного яблока»; Katzenspulwurm (кошачья аскарида) - «гельминт, паразитирующий в организме животных и человека».
Весьма часто в структуру фразеологизмов, функционирующих в научно-популярном медицинском дискурсе, входят фамилии ученых: Kramerverband (воротник Крамера); СореMamlock-Wolffenstein-Reaktion (реакиия Koynа-Мамлока-Волфенштайна); Lateralisation im Weber-Versuch (латерализачия в пробе Вебера); Wernicke-Mann-Haltung (поза Вернике-Манна), а также слова, обозначающие предметы быта: Bambusstabwirbelsäule (бамбуковая палка) - «остеопороз тел позвонков, окостенение дисков и связок позвоночника», и профессии: Fechterstellung (поза фехтовальщи$\kappa a)$ - «выпрямление руки при повороте головы в соответствующую сторону».

\section{Метафоры в научно-популярном медицинском дискурсе}

В научно-популярном медицинском дискурсе широко представлено метафорическое использование общеупотребительных слов. Наиболее востребованы метафоры трех групп - отражающие сходство явлений медицинской сферы с игрой, войной и судом.

Первую группу образуют метафоры, возникающие на основе сходства болезни и лечения с игрой. Как правило, актуализируются такие признаки игры, как риск, стратегия, несправедливость, удача. При этом борьба с болезнью сравнивается с игрой, а несправедливость - с риском, на который нужно пойти, чтобы выиграть (победить болезнь). Приведем некоторые примеры функционирования метафор в исследуемом типе дискурса:

(7) Milchprodukte wie Käse, Joghurt, Quark oder natürlich Milch selbst können verschiedene Medikamente Schachmatt setzen. Das gilt beispielsweise für Antibiotika wie Doxycyclin und Ciprofloxacin (So nehmen Sie Medikamente richtig ein. https://www.senioren-ratgeber.de) - 'Молочные продукты такие, как сыр, йогурт, творог или натуральное молоко могут нейтрализовать (букв: 'поставить мат') некоторые медикаменты. Это распространяется, например, на доксициклин и ципрофлоксацин'.

(8) Man möchte es sich gar nicht vorstellen, aber der menschliche Körper ist ein Tummelplatz für unendlich viele Bakterien (Schwanger: Test auf BStreptokokken sinnvoll? http://www.apothekenumschau.de) - 'Трудно себе представить, но чело- 
веческий организм - это игровая площадка для многочисленных бактерий'.

(9) Die Alpha-Zellen in der Bauchspeicheldrüse produzieren das Hormon Glukagon, das den Blutzuckerspiegel erhöht. Es ist der Gegenspieler zu Insulin (Alpha-Zellen. https://www.diabetesratgeber.net) - 'Альфа-клетки в поджелудочной железе выделяют гормон глюкагон, который повышает уровень сахара, и является противником инсулина'.

Вторую группу формируют метафоры, связанные с военными действиями. Впервые военные метафоры в медицине появились в 80-е гг. XIX в., когда бактерии стали называть Invasoren (захватчики), которые sickerten ein (воен. «проникать в тыл врага»). Тенденция актуальна и по сей день. Так, рак обозначают как врага (Feind), с которым общество ведет войну (Krieg):

(10) Denn je besser man seinen Feind kennt, desto leichter fällt die Wahl der richtigen Waffen (Die besten Therapiemethoden bei Prostatkrebs. https:// www.apotheken-umschau.de) - 'Чем лучше знаешь своего врага (здесь: рак простаты), тем легче подобрать правильное оружие для борьбы с ним'.

Однако не только рак, СПИД, но и другие тяжелые болезни «ведут бой» с человеческим организмом:

(11) Allergien sind in den letzten Jahren immer mehr auf dem Vormarsch. Und so stellen sich die meisten werdenden Mamas im Laufe der Schwangerschaft die Frage: Ist auch mein Baby allergiegefährdet? (OnlineTest: das Allergie-Risiko Ihres Kindes. https://www.babyund-familie.de) - 'В последние годы аллергия перешла в наступление. Многие будущие мамы задаются вопросом: мой ребенок будет подвержен аллергии?';

(12) Einer Untersuchung aus Peking zufolge sind Pickel auf dem Vormarsch, wenn die Werte für Feinstaub, Ozon und andere Umweltgifte steigen (Werden Pickel durch Stress verursacht? https:// www.apotheken-umschau.de) - 'Согласно исследованию, проведенному в г. Пекин, акне атакует человека, когда повышается уровень мелкодисперсной пыли, озона и других токсичных веществ в воздухе'.

Чтобы «бороться с болезнями» (die Krankheiten bekämpfen) и «защищать иммунитет» (das Immunsystem schützen), врачи разрабатывают «военные стратегии» (Kriegsstrategien), используют лекарственные средства как оружие (die Waffen):
(13) Eine weitere hochwirksame Waffe gegen Prostatakrebs ist die moderne Strahlentherapie (Die besten Therapiemethoden bei Prostatkrebs. https:// www.apotheken-umschau.de) - 'Еще одно высокоэффективное оружие против рака простаты - современная лучевая терапия'.

Метафоры третьей группы отражают сходство явлений медицинской сферы со сферой юридической. Так, возбудители заболевания рассматриваются как преступники, заболевание - как преступление. Бактерии, вирусы, неправильное питание, несоответствующее лечение, недостаток витаминов «виновны в нарушении работы организма» и несут «ответственность за преступление»:

(14) Das Gerstenkorn ist eine akute Entzündung der Lidranddrüsen. Meist sind Bakterien (Staphylokokken) schuld (Sehstörungen. https:// www.apotheken-umschau.de) - 'Ячмень представляет собой воспаление слизистой века. Виной этому служат бактерии (стафилококк)'.

(15) Ein Herzinfarkt kann sich ankündigen. Verdächtig sind zum Beispiel Schmerzen im Brustkorb, die bei Belastung oder psychischem Stress auftreten, und dann wieder verschwinden (Herzinfarkt. https:// www.apotheken-umschau.de) - 'Инфаркт может проявлять себя. Подозрение должны вызвать боли в грудине, которые возникают при физической нагрузке или стрессе, а затем вновь исчезают'

(16) Digitalisierung, Druck im Job, Freizeitstress: Experten sagen, der moderne Lebensstil raubt uns den Schlaf (Weshalb viele Menschen schlecht schlafen. https://www.apotheken-umschau.de) - 'Мир цифровых технологий, стресс на работе и в свободное время: эксперты заявляют, что современный стиль жизни ворует у нас сон'.

Использование метафоризированной лексики в научно-популярном медицинском дискурсе способствует его эффективности.

\section{Выводы}

Итак, основной целью медицинского научно-популярного дискурса является информирование, а популяризация научного знания способствует ее реализации. На достижение этой цели направлено использование агентами дискурса разнообразных по своим функциональным свойствам лексических единиц: наиболее широко представлены общеупотребительные слова, существенно уже - обще- 
научные и медицинские термины. Доминирующим жанром в медицинском научно-популярном дискурсе является научно-популярная статья. Попадая в научно-популярный медицинский дискурс, узкоспециализированные тексты адаптируются для непрофессионального получателя, прежде всего это наблюдается в использовании терминологии.

В немецкоязычных интернет-изданиях медицинские термины даются с пояснениями, сопровождаются дублетными лексемами, гипертекстовыми ссылками, содержат интернациональные словообразовательные элементы.

Реализации указанной функции способствуют фразеологизмы и метафоры. В научно-популярном медицинском дискурсе чаще других используются фразеологизмы, возникшие на основе сходства явлений медицинской сферы с явлениями мира животных, а также с бытовыми реалиями, и метафоры, в основу которых положены образы игры, войны, суда.

Развитие лексического состава медицинского научно-популярного дискурса способствует обогащению русского языка, а изучение специфики лексики дискурса исследуемого типа на занятиях со студентами медицинских вузов способствует формированию профессиональных качеств будущих врачей, совершенствованию клинического мышления.

Результаты исследования доказывают перспективность изучения немецкоязычного медицинского научно-популярного дискурса с точки зрения стилистики и прагматики. Перспективным считаем также обращение к медицинским пословицам и поговоркам.

\section{СПИСОК ЛИТЕРАТУРЫ}

Гончаренко Н. В., 2014. РКИ для студентов-медиков: активные и интерактивные формы обучения // Русский язык за рубежом. № 5 (246). С. 4-28.

Денисова Н. В., 2008. Рекламные жанры научнообразовательного дискурса : автореф. дис. ... канд. филол. наук. Томск. 26 с.

Зубкова О. С., 2008. Медицинская метафора как результат культурной фиксации в медицинской терминологии // Вестник Ленинградского государственного университета им. А.С. Пушкина. Серия «Филология». № 5 (19). С. 127-135.

Зубкова О. С., 2011. Метафора в профессиональной семиотике. Курск : Изд-во КГУ. 334 с.
Игнатенко О. П., Фатеева Ю. Г., 2017. Профессиональные фразеологизмы в практическом курсе русского языка как иностранного (на материале языка медицины) // Вестник Волгоградского государственного университета. Серия 2, Языкознание. Т. 16, № 2. С. 181-188. DOI: https://doi.org/10.15688/jvolsu2.2017.2.20.

Карасик В. И., 1998. О категориях дискурса // Языковая личность: социолингвистические и эмотивные аспекты : сб. науч. тр. Волгоград ; Саратов : Перемена. С. 185-197.

Карасик В. И., 2000. О типах дискурса // Языковая личность: институциональный и персональный дискурс : сб. науч. тр. Волгоград : Перемена, 2000. С. 5-20.

Косицкая Ф. Л., 2005. Письменно-речевые жанры рекламного дискурса моды в аспекте межъязыковой контрастивности: на материале французских и русских каталогов моды : автореф. дис. ... канд. филол. наук. Томск. 22 с.

Костяшина Е. А., 2010. Механизмы дискурсивных трансформаций коммуникативной модели «Автор адресат» в текстовом пространстве научно-популярного медицинского журнала // Язык и культура. № 2 (10). С. 28-35.

Момот Е. А., Мартиросян Е. А., Газарянц А. К., 2016. Устойчивые словосочетания. Медицинские фразеологизмы // VIII Международная студенческая конференция «Студенческий научный форум 2016». URL: http://www. scienceforum.ru/2016/2149/25475.

Резанова 3. И., 2008. Трансформации советских стереотипов и мифологем в дискурсе региональных СМИ // Язык и культура. № 3. С. 63-71.

Резанова 3. И., 2012. Дискурсивные стратегии презентации национально-культурной идентичности // Вестник Томского государственного университета. Культурология и искусствоведение. № 4 (8). С. 40-54.

Силантьев И. В., 2004. Текст в системе дискурсных взаимодействий // Критика и семиотика. Вып. 7. С. $98-123$.

Силантьев И. В., 2006. Газета и роман: риторика дискурсных смешений. М. : Языки славянской культуры. $224 \mathrm{c}$.

Соколова О. В., 2014. Типология дискурсов активного воздействия: поэтический авангард, реклама и PR. М. : Гнозис. 304 c.

Сотников Ю. А., 2013. Фразеологизмы в медицине. Орск : [б. и.]. 82 с.

Филлипс Л. Дж., Йоргенсен М. В., 2004. Дискурсанализ. Теория и метод : пер. с англ. / под ред. А. А. Киселевой. Харьков : Изд-во Гуманитарного центра. $336 \mathrm{c}$.

Шамне Н. Л., Шишкина Е. В., 2017. Научно-популярные медицинские интернет-издания на 
немецком языке: структурный и функциональный аспекты // Вестник Волгоградского государственного университета. Серия 2. Языкознание. Т. 16, № 2. C. 143-151. DOI: https://doi.org/10.15688/jvolsu2.2017.2.15

Шишкина Е. В., 2018. Социологическое исследование как жанр медицинского научно-популярного дискурса (на материале немецкого языка) // Филологические науки. Вопросы теории и практики. № 3 (81), ч. 2. С. 382-385.

Gierzyńska Marta Anna, 2013. Metaphorische Phraseologismen in nichtwissenschaftlichen Texten mit medizinischer Thematik // Acta Neophilologica. T. XV, № 2. P. 31-41.

\section{ИСТОЧНИКИ}

http://www.apotheken-umschau.de https://www.senioren-ratgeber.de https://www.baby-und-familie.de https://www.diabetes-ratgeber.net

\section{REFERENCES}

Goncharenko N.V., 2014. The Interactive Forms of Teaching Russian as a Foreign Language for Medical Students. Russkiy yazyk za rubezhom [The Russian Language Abroad], no. 5 (246), pp. 4-28.

Denisova N.V., 2008. Advertising Genres of EducationScience Discourse. Cand. philol. sci. abs. diss. Tomsk. $26 \mathrm{p}$.

Zubkova O.S., 2008. The Medical Metaphor as a Result of Cultural Fixing in Medical Terminology. Vestnik Leningradskogo gosudarstvennogo universiteta imeni A.S. Pushkina. Seriya «Filologiya» [Vestnik of Pushkin Leningrad State University. Series: Philology], no. 5 (19), pp. 127-135.

Zubkova O.S., 2011. Metaphor in Professional Semiotics. Kursk, Izd-vo KGU. 334 p.

Ignatenko O.P., Fateeva Yu.G., 2017. Professional Idioms in the Practical Course of the Russian Language for Foreigners (Based on the Language of Medicine). Vestnik Volgogradskogo gosudarstvennogo universiteta. Seriya 2, Yazykoznanie [Science Journal of Volgograd State University. Linguistics], vol. 16, no. 2, pp. 181188. DOI: https://doi.org/10.15688/jvolsu2. 2017.2.20.

Karasik V.I., 1998. On the Categories of Discourse. Yazykovaya lichnost: sotsiolingvisticheskie $i$ emotivnye aspekty: sb. nauch. tr. Volgograd; Saratov, Peremena Publ., pp. 185-197.
Karasik V.I., 2000. On the Types of Discourse. Yazykovaya lichnost: institutsionalnyy $i$ personalnyy diskurs: sb. nauch. tr. Volgograd, Peremena Publ., pp. 5-20.

Kositskaya F.L., 2005. Written Speech Genres of the Advertising Discourse of Fashion in the Aspect of Interlanguage Contrast (On the Material of French and Russian Fashion Catalogs). Cand. philol. sci. abs. diss. Tomsk. 22 p.

Kostyashina E.A., 2010. The Mechanisms of Discourse Transformations in the Communicative Model 'Author - Addressee' in the Texts of Health Magazines. Yazyk i kultura [Language and Culture], no. 2 (10), pp. 28-35.

Momot E.A., Martirosyan E.A., Gazaryants A.K., 2016. Fixed Collocations. Medical Idioms. VIII Mezhdunarodnaya studencheskaya konferentsiya "Studencheskiy nauchnyy forum 2016». URL: http://www.scienceforum.ru/ 2016/2149/25475.

Rezanova Z.I., 2008. Transformations of Soviet Stereotypes and Mythologemes in the Discourse of Regional Mass Media. Yazyk $i$ kultura [Language and Culture], no. 3, p. 63-71.

Rezanova Z.I., 2012. Discourse Strategies of Presentation of National Cultural Identity. Vestnik Tomskogo gosudarstvennogo universiteta. Kulturologija i iskusstvovedenie [Tomsk State University Journal of Cultural Studies and Art History], no. 4 (8), pp. 40-54.

Silantyev I.V., 2004. The Text in the System of Discourse Interactions. Kritika i semiotika [Critique and Semiotics], no. 7, pp. 98-123.

Silantyev I.V., 2006. Newspaper and Novel: the Rhetoric of Discourse Mixes. Moscow, Yazyki slavyanskoy kultury Publ. 224 p.

Sokolova O.V., 2014. Typology of Active Influence Discourses: Poetic Avant-Garde, Advertising and PR. Moscow, Gnozis Publ. 304 p.

Sotnikov Yu.A., 2013. Phraseological Units in Medicine. Orsk. 82 p.

Phillips L.J., Jorgensen M.V., 2004. Discourse Analysis. Theory and Method. Transl. by A.A. Kiseleva. Kharkov, Izd-vo Gumanitarnogo tsentra. 336 p.

Shamne N.L., Shishkina E.V., 2017. Science-Popular Medical Online Media in German: Structural and Functional Aspects. Vestnik Volgogradskogo gosudarstvennogo universiteta. Seriya 2, Yazykoznanie [Science Journal of Volgograd State University. Linguistics], vol. 16, no. 2, pp. 143-151. DOI: https://doi.org/10.15688/ jvolsu2.2017.2.15.

Shishkina E.V., 2018. Sociological Study as a Genre of Science-Popular Medical Discourse (On the Material of the German Language). Filologicheskie nauki. Voprosy teorii i praktiki 
Н.Л. Шамне, Е.В. Шишкина. Особенности лексического состава медицинского научно-популярного дискурса

[Philological Sciences. Issues of Theory and Practice], no. 3 (81), part 2, pp. 382-385.

Gierzyńcska Marta Anna, 2013. Metaphorische Phraseologismen in nichtwissenschaftlichen Texten mit medizinischer Thematik. Acta Neophilologica, vol. XV, no. 2, pp. 31-41.

\section{SOURCES}

http://www.apotheken-umschau.de https://www.senioren-ratgeber.de https://www.baby-und-familie.de https://www.diabetes-ratgeber.net

\section{Information about the Authors}

Nikolay L. Shamne, Doctor of Sciences (Philology), Professor, Head of Institute of Philology and Intercultural Communication, Volgograd State University, Prosp. Universitetsky, 100, 400062 Volgograd, Russia, nikolay.shamne@volsu.ru, https://orcid.org/0000-0002-5745-8907

Ekaterina V. Shishkina, Candidate of Sciences (Philology), Senior Lecturer, Department of Foreign Languages with the Latin Course, Volgograd State Medical University, Pavshikh Bortsov Sq., 1, 400131 Volgograd, Russia, e.w.shishkina@gmail.com, https://orcid.org/0000-0001-8620-8387

\section{Информация об авторах}

Николай Леонидович Шамне, доктор филологических наук, профессор, директор института филологии и межкультурной коммуникации, Волгоградский государственный университет, просп. Университетский, 100, 400062 г. Волгоград, Россия, nikolay.shamne@volsu.ru, https://orcid.org/ 0000-0002-5745-8907

Екатерина Викторовна Шишкина, кандидат филологических наук, старший преподаватель кафедры иностранных языков с курсом латинского языка, Волгоградский государственный медицинский университет, пл. Павших Борцов, 1, 400131 г. Волгоград, Россия, e.w.shishkina@gmail.com, https://orcid.org/0000-0001-8620-8387 